\title{
Retrospective duration estimation of public events
}

\author{
CHRISTOPHER D. B. BURT and SIMON KEMP \\ University of Canterbury, Christchurch, New Zealand
}

\begin{abstract}
In three experiments, we investigated subjects' retrospective estimation of the duration of publicly reported events such as, for example, the Falkland's war. In Experiment 1, duration estimates were found to be positively correlated with event knowledge, in keeping with Ornstein's (1969) model of duration estimation. Event duration was, however, generally underestimated, suggesting that the relationship between event knowledge and estimated duration might reflect an increase in estimation accuracy. Other results of Experiment 1 were consistent with this interpretation and suggested that the duration estimates might be largely reconstructed. In Ex. periment 2, duration estimates of specific events and general categories of events were found to be highly correlated, and the subjects in Experiment 3 indicated that they used knowledge of the general characteristic of different types of events to estimate event duration. Overall, reallife duration estimates appear to be based on a combination of specific event information and knowledge derived about that category of event.
\end{abstract}

The aim in this research is the investigation of how people estimate the durations of public events that they have read or heard about through the media. For example, for how long did students hold hostages in the United States Embassy in Iran? How long did the Falkland's war last? Such duration estimates can be termed retrospective, in that they are of intervals of time that have been experienced some while ago.

Previous research relevant to the present topic comes mainly from two rather different areas, both of which suggest hypotheses about the way in which people might estimate the durations of public events. First, a large body of research on duration estimation is derived from laboratory investigations of the perception of time. Second, there are a number of recent investigations of how people date the time of occurrence of both public and personally experienced events. For recent reviews of these areas, see, respectively, Fraisse (1984) and Bradburn, Rips, and Shevell (1987).

Studies of perceived duration have typically involved rather short actual durations, often less than 1 min. The interval to be estimated is presented to the subject under controlled laboratory conditions, using, for example, the onset and termination of a light (see, e.g., Rule \& Curtis, 1985) or a tone (see, e.g., Kane \& Lown, 1986) to define the interval, and subjects are asked to estimate the duration immediately after the presentation of the stimulus interval (Eisler, 1976; Fraisse, 1984).

A number of stimulus variables have been found to affect estimated duration in such experiments. For example, an interval that contains complex, unfamiliar, less

We are grateful for the helpful suggestions of three anonymous reviewers. Address all correspondence to Christopher D. B. Burt, Psychology Department, University of Canterbury, Christchurch, New Zealand. predictable, or more numerous components is estimated to be significantly longer than an interval of similar duration containing simpler (see, e.g., Block, 1978, Experiment 2; Ornstein, 1969; Schiffman \& Bobko, 1974), more familiar (see, e.g., Avant \& Lyman, 1975), more predictable (see, e.g., Frankenhaeuser, 1959; Ornstein, 1969), or fewer components (see, e.g., Buffardi, 1971; Fraisse, 1963; Hall \& Jastrow, 1886; Ornstein, 1969; Schiffman \& Bobko, 1977; Thomas \& Brown, 1974). It has also been found that duration estimates are often related to actual duration by a power function whose slope is less than 1.0; longer durations are underestimated, and shorter durations are overestimated (Eisler, 1976; Kane \& Lown, 1986; Kowal, 1987).

Both biological (see, e.g., Hoagland, 1933) and cognitive (see, e.g., Ornstein, 1969; Underwood, 1975) models have been proposed to account for the process of duration estimation. Since it is difficult to see what predictions biological models would permit in the estimation of the duration of public events, we focus on cognitive models.

Ornstein's (1969) model of duration estimation is undoubtedly the most widely recognized (Fraisse, 1984), and it has given rise to considerable experimentation. This model, often referred to as the "storage size hypothesis," proposes that estimated duration is proportional to the information stored in memory about the event or interval at the time of estimation. Hence the model explains the finding that estimated duration is proportional to the number and complexity of elements in the interval to be estimated. Furthermore, it accounts for time-order error. Typically, when two intervals of equal duration are presented to a subject in succession and estimates of both intervals' durations are obtained, the first interval presented is estimated to be shorter than the second (Al- 
lan, 1977; Hellstrom, 1977; Woodworth \& Schlosberg, 1954). The storage size model accounts for the time-order error effect through the assumption that "when some period elapses before an interval is to be judged ..., some items should drop out of storage and the experience of duration of that interval shortens" (Ornstein, 1969, p. 48).

Ornstein's (1969) model suggested at least two testable hypotheses for the present study. First, public events about which more is known or remembered should, on the average, be estimated as longer than those about which less is known or remembered. Some evidence related to this hypothesis comes from eyewitness studies (Loftus, 1979; Loftus, Schooler, Boone, \& Kline, 1987). For example, Loftus et al. (1987) tested this hypothesis using free recall and accuracy-of-memory measures of a 30-sec videotaped bank robbery. Neither measure of storage size was related to estimated duration, although a significant trend toward overestimation of the duration of the robbery was found.

The second hypothesis concerns the retention interval, or the time between an event and its recall: The duration of older events should be estimated as shorter than that of more recent ones of comparable actual duration. There is already some evidence that the predicted effect (timeorder error) is not found for duration estimates of autobiographical events. Douglas and Blomfield (1956) used hospital records to assess the accuracy of mothers' recall of their children's hospitalization duration. A significant tendency toward overestimation of hospitalization duration was found, and overestimation increased as the retention interval increased. Mednick and Shaffer (1963) also reported a tendency toward overestimation when 14 mothers were asked to estimate how long they had breastfed one of their children. Pediatricians' records were used to check the estimates, but no data were reported on actual duration or retention intervals.

Underestimation of autobiographical event duration has also been found in some situations. Pyles, Stolz, and Macfarlane (1935) used archival records obtained from hospitals, physicians, and public health nurses to assess the accuracy of mothers' estimates of gestation period and duration of labor. The estimates were obtained approximately 21 months after the events. A correlation of .61 was obtained between estimates of duration of labor and recorded duration. Overall, the 158 mothers tended to underestimate the actual duration. Duration of gestation was, on the other hand, generally estimated accurately with no discernible error tendency. No data on actual duration were reported for this event, although one might assume that it would have been around 9 months, as the respondents probably did as well.

These studies suggest that retrospective duration estimates of autobiographical events are not veridical, a finding that is consistent with the laboratory studies of perceived duration. Furthermore, the tendency toward event duration overestimation reported by Douglas and Blomfield (1956) and Mednick and Shaffer (1963) is consistent with Loftus et al. (1987). However, Pyles et al.
(1935) found a tendency toward underestimation, and some of their results suggest that retrospective estimates of event duration might be reconstructed rather than remembered.

That duration estimates might be reconstructed rather than remembered is suggested if we consider real-life situations. For example, a painting contractor may be asked how long it will take to paint a particular house. Under these conditions, a duration estimate must be either guessed or constructed. When it is considered that a highly inaccurate guess might result in actual financial loss, it is probable that the required duration estimate is constructed on the basis of past experience rather than guessed. In general, the reconstruction of event duration might produce either overestimation or underestimation, perhaps depending on the similarity of past events to the target event.

It is possible to regard the process of dating an event as an example of duration estimation, and certain authors have taken this viewpoint (e.g., Bratfisch, Ekman, Lundsberg, \& Kruger, 1971; Ferguson \& Martin, 1983; Fraisse, 1984; Furlong, 1951). Lieury, Caplain, Jacquet, and Jolivet (1979), who sought to link event dating and duration estimation, used Ornstein's (1969) model in an attempt to explain why event age is often underestimated. In general, however, theories to explain errors in dating have not relied heavily on models of duration estimation (see Brown, Rips, \& Shevell, 1985; Huttenlocher, Hedges, \& Prohaska, 1988; Rubin \& Baddeley, 1989).

Evidence that event dates are reconstructed has been found in a number of dating studies (e.g., Burt, in press; Baddeley, Lewis, \& Nimmo-Smith, 1978; Brown, Shevell, \& Rips, 1986; Friedman \& Wilkins, 1985; Kemp, 1988; Linton, 1975; Loftus \& Marburger, 1983; Thompson, 1982; Wagenaar, 1986; White, 1982). For example, Friedman and Wilkins (1985) presented subjects with generic descriptions of events (e.g., "A member of the royal family is assassinated" [p. 172]) and found evidence that the month and hour of the occurrence information were reconstructed. Kemp (1988) showed that similar dating biases were associated with historical and recent public events, even though factors relating to age of memory or events occurring in the retention interval can play no role in dating the former.

It seems quite possible that reconstructive or inferential processes of the kind suggested by the dating studies and by Pyles et al. (1935) might be used during retrospective estimation of the duration of a public event. Thus, a further hypothesis considered in the following experiments was that duration estimates are in large part reconstructed or inferred.

\section{EXPERIMENT 1}

\section{Method}

Questionnaire. Thirty-six distinguishable public events, all of which occurred between 1978 and 1986, were selected, subject to the criterion that each had a distinct beginning and end, and a du- 
ration longer than 1 day. The major part of the questionnaire consisted of descriptions of each of these events, followed by an instruction to estimate how long the event had lasted. Actual examples of these descriptions include: "Mr. Aldo Moro, former Prime Minister of Italy, was kidnapped by the Red Brigade urban-guerrilla group. Sometime later his body was found in the boot of a car in central Rome"; and "Pope John Paul II went to Poland to visit his homeland. It was the first visit by a Pope to a communist country." Actual event duration was determined from the media reports associated with the events; the days on which the event began and ended were counted as complete days. Actual duration ranged from 2 to $\mathbf{4 4 8}$ days. The actual durations and beginning dates of each of the 36 events are shown in Table 1 . The actual duration and age of the events, defined by the day they began, were not significantly correlated (Spearman's $\rho=-.27$, n.s.). All correlations reported in this study are Spearman rank, and significance tests were twotailed.

The respondents were also asked to rate how much they remembered of each event on a 7-point scale ranging from I cannot remember this event (1) to I remember it perfectly (7). A preliminary experiment conducted with a separate sample and 11 of the events established that the scale ratings were positively correlated with performance on 10 true-false questions on specific features of the events.
The 36 events were randomly assigned to positions in the questionnaire. Questions relating to the respondents' sex and age were located on the cover page, along with instructions.

Subjects. Twenty-three male and 30 female undergraduate psychology students at the University of Canterbury completed the questionnaire. All were 20 years old at the time of the experiment. (In the preliminary experiment, it was found that public event knowledge was correlated with age.)

Procedure. The subjects completed the questionnaire individually. They were instructed to read each event description, rate how much they remembered of the event, and estimate its duration. They were asked to give a duration estimate even if they could not remember the event itself. Three example questions (not included in the questionnaire) were displayed on an overhead projector to illustrate the task. The subjects required approximately $20 \mathrm{~min}$ to complete the questionnaire. The experiment was carried out in October 1987.

\section{Results}

Median duration estimates were computed for each of the 36 events. Table 1 shows the median duration estimate, actual duration, date on which the event began, mean knowledge rating, and median signed, absolute, and

Table 1

Beginning Date, Actual Duration, Median Estimated Duration, Mean Knowledge Rating and Median Percentage, Absolute and Signed Error for Each Public Event Used in Experiment 1

\begin{tabular}{|c|c|c|c|c|c|c|c|}
\hline $\begin{array}{c}\text { Brief Event Description } \\
\text { and Abbreviation }\end{array}$ & $\begin{array}{c}\text { Date Event } \\
\text { Began }\end{array}$ & $\begin{array}{c}\text { Actual } \\
\text { Duration } \\
\text { (Days) }\end{array}$ & $\begin{array}{c}\text { Median } \\
\text { Duration } \\
\text { Estimate } \\
\text { (Days) } \\
\end{array}$ & $\begin{array}{c}\text { Median } \\
\text { Percentage } \\
\text { Error } \\
\text { (Days) } \\
\end{array}$ & $\begin{array}{c}\text { Median } \\
\text { Absolute } \\
\text { Error } \\
\text { (Days) } \\
\end{array}$ & $\begin{array}{c}\text { Median } \\
\text { Signed } \\
\text { Error } \\
\text { (Days) } \\
\end{array}$ & $\begin{array}{c}\text { Mean } \\
\text { Knowledge } \\
\text { Rating }\end{array}$ \\
\hline Aldo Moro kidnapping (AM) & 16 March 1978 & 55 & 14.0 & 74.5 & 41 & -41 & 1.7 \\
\hline Cook Island's election scandal (SAH) & 1 April 1978 & 117 & 14.0 & 88.0 & 103 & -103 & 1.8 \\
\hline Pope John Paul I's reign (PPI) & 27 Aug 1978 & 33 & 90.0 & 172.7 & 57 & 57 & 2.8 \\
\hline Pope John Paul II visits Poland (PPI) & 2 June 1979 & 9 & 7.0 & 55.6 & 5 & -2 & 3.1 \\
\hline Carless days in NZ (CD) & 30 July 1979 & 319 & 240.0 & 43.6 & 139 & -79 & 3.9 \\
\hline Abbotsford emergency (A) & 6 Aug 1979 & 36 & 13.0 & 72.2 & 26 & -23 & 3.4 \\
\hline Soviet Airliner held in NY (SB) & 26 Aug 1979 & 3 & 2.0 & 66.7 & 2 & -1 & 1.4 \\
\hline U.S. Embassy occupation (OUE) & 4 Nov 1979 & 442 & 28.0 & 93.7 & 414 & -414 & 2.4 \\
\hline Great Mosque seized (GM) & 20 Nov 1979 & 14 & 6.0 & 67.9 & 9.5 & -8 & 1.5 \\
\hline Paul McCartney arrested (PMC) & $14 \operatorname{Jan} 1980$ & 12 & 4.0 & 66.7 & 8 & -8 & 2.4 \\
\hline Hostages Iranian Embassy London (IEL) & 30 April 1980 & 7 & 4.0 & 57.1 & 4 & -3 & 2.2 \\
\hline Mangere College play (MP) & 3 May 1980 & 3 & 7.0 & 133.3 & 4 & 4 & 1.1 \\
\hline Clark murder trial (TJC) & 6 Jan 1981 & 123 & 36.5 & 81.7 & 100.5 & -86 & 2.7 \\
\hline Walesa visits Rome (LW) & 13 Jan 1981 & 7 & 7.0 & 57.1 & 4 & 0 & 1.6 \\
\hline Suspected foot and mouth outbreak (TPF) & 11 Feb 1981 & 11 & 7.0 & 45.5 & 5 & -4 & 3.2 \\
\hline Pacific Charger runs aground (PC) & 21 May 1981 & 15 & 6.0 & 66.7 & 10 & -9 & 2.1 \\
\hline Springbok tour (ST) & 19 July 1981 & 55 & 21.0 & 61.8 & 34 & -34 & 4.5 \\
\hline Rexin Industrial sit-in (RCF) & 1 Sept 1981 & 96 & 5.0 & 94.8 & 91 & -91 & 1.3 \\
\hline Sweden detains Soviet submarine (SS) & 27 Oct 1981 & 11 & 14.0 & 63.6 & 7 & 3 & 2.1 \\
\hline Falkland's war (F) & 2 April 1982 & 73 & 35.0 & 61.6 & 45 & -38 & 4.5 \\
\hline Climbers trapped on Mount Cook (MC) & 15 Nov 1982 & 14 & 6.0 & 57.1 & 8 & -8 & 3.8 \\
\hline Dozier kidnapping (JD) & $17 \operatorname{Dec} 1982$ & 42 & 21.0 & 66.7 & 28 & -21 & 1.4 \\
\hline Australian bushfire (AB) & 16 Feb 1983 & 2 & 12.5 & 525.0 & 10.5 & 10.5 & 3.2 \\
\hline Royals visit New Zealand (R) & 17 April 1983 & 13 & 7.0 & 46.2 & 6 & -6 & 3.5 \\
\hline Discovery of Hitler diaries (S) & 22 April 1983 & 17 & 21.0 & 64.7 & 11 & 4 & 3.4 \\
\hline Maori protest march $(\mathrm{H})$ & 28 Jan 1984 & 10 & 5.0 & 60.0 & 6 & -5 & 2.2 \\
\hline Search for psychiatric patient (BDC) & 22 Feb 1984 & 9 & 9.5 & 50.0 & 4.5 & .5 & 2.0 \\
\hline Police besiege Libyan Bureau London (YF) & 17 April 1984 & 10 & 3.0 & 70.0 & 7 & -7 & 2.6 \\
\hline Gloria Kong kidnapping (GK) & 29 June 1984 & 3 & 4.0 & 66.7 & 2 & 1 & 3.2 \\
\hline John Kirk extradited from U.S.A. (JK) & 7 July 1984 & 448 & 134.0 & 70.1 & 314 & -314 & 3.5 \\
\hline Wizard temporarily resigns (W) & 3 Sept 1984 & 30 & 21.0 & 53.3 & 16 & -9 & 3.1 \\
\hline Baby Fae heart transplant (BF) & 26 Oct 1984 & 22 & 14.0 & 59.1 & 13 & -8 & 2.6 \\
\hline Riots in New Caledonia (NC) & $12 \operatorname{Jan} 1985$ & 2 & 10.5 & 425.0 & 8.5 & 8.5 & 2.1 \\
\hline Achillo Lauro hijacked (AL) & 7 Oct 1985 & 3 & 5.5 & 83.3 & 2.5 & 2.5 & 2.3 \\
\hline Daniloff arrested (ND) & 29 Aug 1986 & 13 & 26.0 & 100.0 & 13 & 13 & 2.8 \\
\hline Stars \& Stripes beats KZ7 (KZ7) & 5 Oct 1986 & 12 & 28.0 & 133.3 & 16 & 16 & 4.8 \\
\hline Overall (Means) & & 58.08 & 24.6 & 95.9 & 43.75 & -33.3 & 2.6 \\
\hline
\end{tabular}


percentage error for each of the 36 events. (Signed error was calculated through subtraction of the actual event duration from the estimated duration; for absolute error, the sign of the estimate was ignored. For percentage error, the absolute error was divided by the actual event duration.) The absolute and percentage error medians both give an indication of estimation accuracy. Inspection of these medians indicates that estimated duration was often quite close to actual event duration (absolute error), and estimation accuracy was reasonably similar across the events (percentage error). Examination of the distribution of the absolute errors showed that only $3.4 \%$ of the duration estimates were exactly correct, while $11.6 \%$ were within 2 days of the actual duration, $14.7 \%$ were in error by $3-5$ days, and $18.9 \%$ were within $6-10$ days of actual event duration.

A significant $(p<.01)$ correlation of .64 was obtained between actual and median estimated duration, indicating that the longer the actual event duration, the longer the estimated duration. An exponent of 0.50 and a correlation of 0.69 were obtained when the logarithm of the median duration estimates was regressed on the logarithm of the actual durations. This analysis indicates a tendency for the short-duration events to be overestimated and the long-duration events to be underestimated, a feature that can also be clearly discerned in Table 1 . This exponent is smaller than the exponent value of 0.90 typically found in traditional duration estimation research (Eisler, 1976). The overestimation of short-duration events may indicate a boundary effect. Rubin and Baddeley (1989) found evidence of similar boundary effects in date responses (see also Huttenlocher et al., 1988).

There was no significant correlation between the age of the event and its median estimated duration $(\rho=-.02$, $n . s$.) or between mean knowledge rating and actual event duration $(\rho=.23$, n.s. $)$. Hence, in contradiction to the first hypothesis derived from Ornstein's theory, no evidence of an effect of retention interval on estimated duration was found. However, storage size may not have decreased sufficiently for an effect to be obtained, because the negative correlation of -.26 between event age and its mean knowledge rating was not significant.

Correlating median duration estimates and mean knowledge ratings produced a moderate yet significant $(p<.05)$ correlation of .42 . Thus, the better known events were on the average estimated to have lasted longer. This result provides some support for Ornstein's (1969) "storage size" hypothesis. However, as can be seen in Table 1, the general tendency was for event durations to be underestimated. The median estimated durations of 25 of the 36 events are underestimates, and the overall median signed error of -6.5 days shows underestimation. Furthermore, $86.8 \%$ of the subjects showed a negatively signed error overall, a tendency toward underestimation. Therefore, the observed positive relationship between event knowledge and estimated duration might be alternatively explained as a tendency for esti- mated duration to increase in accuracy as event knowledge increases.

In order to examine the effect of event knowledge on duration estimation more closely, further analyses were performed. First, the knowledge ratings for each subject and event were dichotomized. Knowledge ratings of 1 ("I cannot remember the event") were taken to be indicative of forgotten events or events that the subject had not heard of. Events given a knowledge rating from 2 to 7 were taken to be remembered events. Then, for each event, the median duration estimate of the subjects who could not remember the event was calculated, and, similarly, the median duration estimates of subjects who remembered the particular event. The number of subjects who did or did not remember the event varied with the event, and there were three events (CD, ST, and F; see Table 1) that were remembered by all the subjects.

When the two groups of estimates were compared (over the 33 events for which both remembered and notremembered estimates were available) no significant difference was found $[t(32)=-.82$, n.s.]. Indeed, for six of the events, the median duration estimates were identical for the two groups. Further evidence that the two groups of estimates were similar was found when the median signed error of the estimates $[t(32)=0.82$, n.s. $]$ and the median absolute error of the estimates $[t(32)=0.96$, n.s.] of each group were compared, and when actual and estimated event duration were correlated for each group separately $(\rho=.68, p<.01$, and $\rho=.46, p<.01$, for the remembered and forgotten event groups, respectively).

\section{Discussion}

The overall effect of these analyses is to call the meaning of the correlation between median duration estimates and mean knowledge ratings into question. Although the existence of this correlation supports Ornstein's (1969) hypothesis, the finding that event durations were generally underestimated and that increased event knowledge decreased the size of the underestimation argues for an "estimation accuracy" explanation of the event knowledge effect. Moreover, the degree to which an event is remembered had only a small effect on estimated duration. Indeed, not remembering the events at all did not significantly increase estimation error (absolute error) or significantly change the nature of the estimates made (signed error) relative to estimates given by subjects who remembered the event.

The similarity of the estimates provided by subjects who allegedly did or did not remember the events suggests either that both groups were simply guessing - an implausible hypothesis in view of the accuracy of many of the estimates-or that some sort of inferential or reconstructive process may have been involved.

Reconstructing event duration may involve the use of general event knowledge already stored in memory, and information provided in the event description. Individuals are constantly exposed to information about public events. 
Over time, many similar, though distinguishable, events occur. Similar events can be categorized into types (e.g., natural disasters, wars, an official visit to a country). As he or she encounters more instances of a specific type of event, the individual may develop a general representation of that type of event's characteristics. Time information, such as event duration, may be part of this general event knowledge. The extent of this general event knowledge, for any specific type of event, might be assumed to vary in relation to the number of category members encountered.

To provide subjects with a specific event description, as was done in Experiment 1, might allow them to access a specific memory of that event, or to categorize the described event as a particular type and access their general event knowledge for that type of event, or both. When both specific and general event knowledge can be recalled, the specific event knowledge may help reduce the error in an inferred duration estimate, particularly if the specific event is not a representative member, in terms of actual duration, of its event category. That is, if the event appears to be typical of an event category but its duration is atypical for some reason, specific event knowledge should reduce the estimation error.

This reasoning provides two testable hypotheses. If the duration of a specific event is estimated by inference from general knowledge of that type of event, then the estimated duration of a specific event should be similar to the estimated duration of the same event described in general terms. Furthermore, if general event knowledge becomes more elaborate as the number of similar events encountered increases, inferred duration estimates of frequently occurring events should show less between-subject variance, and perhaps also be slightly more accurate, than should inferred duration estimates of less frequently occurring events. Each of these hypotheses was tested in Experiment 2.

\section{EXPERIMENT 2}

Two experimental hypotheses were tested: first, that duration estimates given by subjects who cannot remember or who have never heard of a specific event will be similar to estimates made by subjects given a general description of the same event; second, that the duration estimates of high-frequency events will show less betweensubject variance than those of low-frequency events.

\section{Method}

Questionnaire. Thirty-three of the 36 event descriptions used in Experiment 1 were transformed into general event descriptions. For example, the "Aldo Moro" and the "Pope John Paul II" events from Experiment 1 became the following: "A prominent politician is kidnapped by an urban-guerrilla group. Some time later his body is found," and "A prominent religious leader made an official visit to a foreign country."

A brief preliminary experiment, in which 81 subjects rated the frequency of occurrence in the previous 10 years of each of the 33 general events, allowed 10 low- and 10 high-frequency events to be selected. Selection was based on both the median frequency of occurrence estimates, and their interquartile deviations. That is, the selected low- and high-frequency events had not only the smallest and largest medians, respectively, but also the smallest interquartile deviations.

Two questionnaires were constructed. The general questionnaire contained the 20 selected general event descriptions randomly assigned to a position in the questionnaire. The specific questionnaire contained the $\mathbf{2 0}$ corresponding specific event descriptions used in Experiment 1, assigned to matched positions. Both questionnaires required duration estimates. Questions relating to the subjects' age and sex were located on the cover page, along with instructions.

Subjects. Subjects completed either the general or the specific event questionnaire. Twenty-one males and 27 females, with an age range of 17-41 years, from the introductory psychology course at the University of Canterbury, completed the general event questionnaire. Thirty-five male and 64 female subjects from the same course, with ages in the range of $17-45$ years, completed the specific event questionnaire.

Procedure. Both groups of subjects were instructed to read each event description carefully and estimate the event's duration. Subjects who completed the specific event questionnaire were also instructed to indicate whether they remembered the event in the space provided. All subjects completed their questionnaire in April 1988, and took approximately $15 \mathrm{~min}$ to do so.

\section{Results}

As in Experiment 1, the estimates obtained with the specific event questionnaire were divided into two groups on the basis of whether or not the subject indicated he or she remembered the event. The median duration estimate was then calculated for each event for these two groups (specific remembered and specific not remembered), and for the general event questionnaire estimates. Table 2 shows the 20 median duration estimates for each of these groups. Actual event duration is also shown. Inspection of the median duration estimates shown in Table 2 suggests that they are similar across the groups.

This was confirmed when the three groups of median estimates were correlated. Significant $(p<.01)$ positive correlations were obtained between the general event and specific not-remembered median estimates $(\rho=.72)$, between the specific remembered and general event median estimates $(\rho=.71)$, and between the specific notremembered and specific remembered median estimates $(\rho=.77)$.

Further evidence of between-group estimate similarity was found when median estimated duration was compared across the three groups using paired-sample $t$ tests [general and specific not-remembered, $t(19)=1.75$, n.s.; general and specific remembered, $t(19)=1.18$, n.s.; and specific remembered and not-remembered, $t(19)=0.45$, n.s.]. Similarly no significant differences were found when median estimated duration and actual event duration were compared [general, $t(19)=0.47$, n.s.; specific notremembered, $t(19)=0.72$, n.s.; and specific remembered $t(19)=1.40$, n.s. $]$. The three groups of estimates not only appear to vary similarly with actual event duration, as is indicated by the high between-group estimate correlations, but also show the same extent of estimation error, indicated by the $t$ test results. 
Table 2

Median Duration Estimates Obtained with the General Events

and the Specific Events from Subjects Who Did

and Did Not Remember the Events

\begin{tabular}{|c|c|c|c|c|}
\hline \multirow[b]{2}{*}{ Event } & \multirow[b]{2}{*}{$\begin{array}{c}\text { Actual } \\
\text { Duration }\end{array}$} & \multicolumn{3}{|c|}{ Median Duration Estimates (Days) } \\
\hline & & $\begin{array}{l}\text { General Event } \\
\text { Questionnaire }\end{array}$ & $\begin{array}{l}\text { Specific Event } \\
\text { Questionnaire: } \\
\text { Not Remembered }\end{array}$ & $\begin{array}{l}\text { Specific Event } \\
\text { Questionnaire: } \\
\text { Remembered }\end{array}$ \\
\hline \multicolumn{5}{|c|}{ High-Frequency Events } \\
\hline PPII & 9 & 7.5 & 8.5 & 7 \\
\hline A & 36 & 10 & 7 & 13 \\
\hline $\mathrm{PC}$ & 15 & 10 & 4 & 8.5 \\
\hline $\mathbf{R C F}$ & 96 & 4 & 5 & 9 \\
\hline MC & 14 & 4.5 & 5 & 7 \\
\hline $\mathbf{A B}$ & 2 & 5.5 & 5 & 7 \\
\hline $\mathbf{R}$ & 13 & 9 & 5 & 7 \\
\hline $\mathbf{H}$ & 10 & 1 & 3 & 3 \\
\hline BF & 22 & 27 & 7 & 12 \\
\hline $\mathrm{NC}$ & 2 & 4 & 14 & 14 \\
\hline \multicolumn{5}{|c|}{ Low-Frequency Events } \\
\hline SAH & 117 & 23 & 21 & 23.5 \\
\hline PPI & 33 & 360 & 255 & 90 \\
\hline TJC & 123 & 105 & 60 & 90 \\
\hline LW & 7 & 14 & 7 & 4 \\
\hline TPF & 11 & 7 & 5 & 10.5 \\
\hline SS & 11 & 26.5 & 14.5 & 14 \\
\hline BDC & 9 & 5 & 8 & 6 \\
\hline JK & 448 & 148 & 60 & 120 \\
\hline w & 30 & 21 & 21 & 28 \\
\hline $\mathrm{AL}$ & 3 & 4 & 5 & 5 \\
\hline
\end{tabular}

In order to assess further the proposition that the estimates given by subjects who did not remember the events and the estimates based on general event descriptions were similar, between-group estimation accuracy was examined. Absolute and signed error scores were calculated for each of the three groups of estimates and compared, using paired-sample $t$ tests (the procedures involved for calculating error scores were identical to those used in Experiment 1). None of the comparisons with signed error scores produced a significant difference [general and specific not-remembered, $t(19)=1.75$, n.s.; general and specific remembered, $t(19)=1.18$, n.s.; and specific remembered and not-remembered, $t(19)=0.45$, n.s.]. Nor were any significant differences found for absolute error [general and specific not-remembered, $t(19)=1.46$, n.s.; general and specific remembered, $t(19)=0.90$, n.s.; and specific remembered and specific not-remembered, $t(19)=1.50$, n.s.]. Hence the subjects who did not remember the events and the subjects given only general event descriptions made very similar estimation errors to those of the subjects who actually remembered the events.

The two groups of median duration estimates obtained in Experiment 1 (i.e., estimates given by subjects that did and did not remember the events for the 20 events used in Experiment 2) were also correlated with the three groups of estimates obtained in this experiment. The correlation between the two groups of subjects who did not remember the events was high $(\rho=.73, p<.01)$, as was the correlation between the two groups of subjects who did remember the events $(\rho=.88, p<.001)$. Furthermore, the general event questionnaire estimates showed a stronger correlation with the not-remembered $(\rho=.83, p<.001)$ than with the remembered $(\rho=.57$, $p<.05)$ estimates from Experiment 1 .

Overall, the specific event questionnaire results are consistent with those obtained in Experiment 1, in that estimates given by subjects who did and those who did not remember the events were very similar. Furthermore, the results support the first experimental hypothesis, in that the estimates given by the subjects who did not remember the specific events were highly correlated with those given by subjects presented with general event descriptions only. The results suggest that duration was reconstructed on the basis of the available information-that is, the cues contained within the event description and general event knowledge gained from past experience.

The second experimental hypothesis, that "duration estimates of the high-frequency events will be more accurate and show less between-subject variation than those of the low-frequency events," focuses on the effect of "past experience" in the inferential duration estimation process. In order to test this hypothesis, median absolute error and the standard deviation of estimated duration of the 10 highand 10 low-frequency events were compared for each of the three groups. Because the actual durations of the highand low-frequency events were different, comparisons were performed, using analysis of covariance with actual event duration being the covariate. 
The mean absolute error (after adjustment for the effect of the covariate) varied in the predicted direction for all three groups. General event group adjusted means were 35.52 and 70.34 , specific not-remembered adjusted means were 42.84 and 57.72 , and specific remembered means were 38.87 and 39.83 for the 10 high- and low-frequency events, respectively. However, none was found to be significantly different. Similarly adjusted mean standard deviations varied in the predicted direction for all groups: general, 36.21 and 117.29; specific not-remembered, 22.22 and 67.40; and specific remembered, 25.81 and 65.55 for the 10 high- and low-frequency events, respectively. Although none of these means was found to be significantly different, when the standard deviations of the general and specific not-remembered estimates were averaged, the difference between the high- and low-frequency events was found to be significant $[F(1,17)=4.436$, $p<.05]$. The high-frequency events' mean standard deviation (29.20) was smaller than the low-frequency events' (92.56) as predicted. No other significant differences were found for either standard deviation or absolute error when averaged across different groups of estimates.

Overall, these results suggest that the duration estimates of all the groups probably contained a high proportion of inference. The consistency of the direction of the adjusted mean differences for both absolute error and standard deviation across the three groups further strengthens this argument.

\section{Discussion}

Although the results of Experiment 1 and Experiment 2 are generally consistent with the hypothesis that subjects reconstructed event duration, the nature of the reconstructive process is not completely clear. We have suggested that event duration may be reconstructed on the basis of general knowledge of event categories, but subjects might have adopted an "availability" strategy as a basis for reconstruction. Under this strategy, a specific event in the target event's category might be remembered and the duration of this event used to estimate the target event's duration. Note that, in using this strategy, subjects need not have recalled the duration of the specific event asked for, but that of another related event, such as another kidnapping or religious leader's visit.

Several aspects of the data from Experiment 1 argue against duration reconstruction's being based on specific event availability. Specific event availability is questioned by the finding in Experiment 1 that only $68.3 \%$ of the knowledge ratings were greater than 1 , indicating that the event was remembered. Indeed, only half of the events $(n=18)$ were remembered by at least $80 \%$ of the subjects. These percentages probably represent the upper bound of specific event memory, because they are based on recognition of event descriptions, and they suggest that subjects may often not be able to remember specific events. Furthermore, remembering an event does not necessarily mean that its duration is remembered.
The effect of event frequency on between-subject estimation variance (standard deviation of duration estimates) found in this experiment is also inconsistent with duration reconstruction's being based on specific event recall. Duration reconstruction based on specific event availability would predict a rather different result. Duration events categorized as similar (e.g., royal visits) almost certainly vary in actual duration. If different occurrences are used in an availability manner by different subjects, one might expect an increase in between-subject estimation variance for high-frequency events, not the decrease observed in this experiment.

These considerations, however, do not rule out the specific event availability hypothesis. Experiment 3 was designed to investigate the possibility that duration estimate reconstruction involved the use of specific events.

\section{EXPERIMENT 3}

\section{Method}

Questionnaire. Two questionnaires were prepared. Both contained the 20 general event descriptions used in Experiment 2 and called for duration estimates. On one questionnaire (Duration Estimation Process), subjects were asked to indicate which of four listed estimation processes, or any other that they should wish to specify, best described how they generated their estimate. On the other questionnaire (Specific Event Recall), the subjects were asked if a specific occurrence of the type of event described in the general description could be recalled. If so, the subjects were to describe it.

Estimation processes listed in the Duration Estimation Process questionnaire were the following: (1) "I counted the number of separate components or subevents of this type of event and based my duration estimate on this count," (2) "My duration estimate is based on general knowledge and logical characteristics of this type of event," (3) "My duration estimate is a wild guess that is in no way based on any knowledge of this type of event," and (4) "I remembered the duration of a specific instance of the type of event described in the event description. I then used this duration information as the basis for my duration estimate."

Subjects. Introductory psychology students at the University of Canterbury completed either the duration estimation process or the specific event recall questionnaire. Twenty-one females and 11 males between the ages of 18 and 52 years completed the former questionnaire, and 11 males and 12 females with ages in the range 17-50 years the latter.

Procedure. Both questionnaires were distributed to the subjects during class time. The subjects were instructed to read the instructions and to return their questionnaire in class on the following day. The experiment was conducted in July 1990.

\section{Results and Discussion}

Median estimated duration was calculated for each event and each questionnaire. Significant correlations were obtained between the median estimates from the two questionnaires $(\rho=.89, p<.001)$, and when these estimates were correlated with the general event questionnaire median estimates from Experiment $2, \rho=.91(p<.001)$ and $\rho=.86(p<.001)$ for the duration estimation process and specific event recall estimates, respectively. These results indicate that there was reasonable consistency across the experiments in estimation of the duration of different types of public events, and that sub- 
jects in Experiment 2 and in this experiment probably used similar processes to estimate duration.

Analysis of the duration estimation process questionnaire revealed that $6.5 \%$ of the duration estimates, according to the subjects, were based on an event component count, $38.8 \%$ were obtained from general knowledge of the event category, $22.2 \%$ were guessed, and $30.5 \%$ were based on recall of a specific event. The remaining $2.0 \%$ were generated with "other" strategies. Thus subjects considered themselves to be using both specific events and general knowledge in estimating the duration of different types of events.

The first two columns of Table 3 show the number of subjects who claimed to have estimated event duration using general and specific event knowledge, respectively. Clearly, the use of one or the other strategy varied with the particular general event description.

On the average, each subject completing the specific event recall questionnaire described 9.0 (out of 20 possible) specific events. In total, then, 208 descriptions were obtained. The last column of Table 3 shows the distribution of these recalled specific events over the different general event types. It is again noticeable that some general event descriptions were more likely to elicit descriptions of specific events. In fact, there is a significant correlation $(\rho=.79, p<.01)$ between these results and the number of subjects who stated that they used a specific event to estimate durations in the duration estimation process questionnaire (i.e., between columns 2 and 3 of Table 3). Thus, general events that elicited recall of specific events were also more likely to have their durations estimated with the aid of specific events.

Of the 208 specific event descriptions obtained from the specific event recall questionnaire, 34 did not contain sufficient detail to identify the event the subject had in mind. Of the remaining 174 descriptions, 49 were of events used in Experiment 1-that is, the actual specific events on which the general event descriptions were based. Indeed, for three general event descriptions (SS, BDC, and $\mathrm{AL}$; see Table 1 for explanations of abbreviations) every elicited specific event was the actual specific event used in Experiment 1, and for another four event types (PPI, TJC, TPF, and PC), at least half of the events described were the relevant Experiment 1 events. These results suggest that the particular specific events used in Experiments 1 and 2 were often the most memorable events in that category of events, and hence that subjects asked to estimate the durations of these specific events

Table 3

Number of Subjects Completing the Duration Estimation Process Questionnaire Who Claimed to Use General Knowledge or Knowledge of a Specific Event When Estimating Duration in Experiment 3

\begin{tabular}{cccc}
\hline & $\begin{array}{c}\text { Number of Subjects } \\
\text { Claiming to Use } \\
\text { General Knowledge } \\
(\text { Maximum =32) }\end{array}$ & $\begin{array}{c}\text { Number of Subjects } \\
\text { Claiming to Use a }\end{array}$ & $\begin{array}{c}\text { Number of Subjects } \\
\text { Describing Specific }\end{array}$ \\
Event & Specific Event & Events \\
(Maximum =32) & (Maximum=23) \\
\hline
\end{tabular}

\begin{tabular}{lrrr} 
PPII & \multicolumn{3}{c}{ High-Frequency Events } \\
A & 15 & 16 & 18 \\
PC & 16 & 12 & 21 \\
RCF & 10 & 4 & 6 \\
MC & 12 & 12 & 5 \\
AB & 11 & 17 & 20 \\
R & 16 & 12 & 18 \\
H & 8 & 22 & 22 \\
BF & 17 & 11 & 22 \\
NC & 14 & 13 & 6 \\
Subtotal & 10 & 16 & 16 \\
& 129 & 135 & 154
\end{tabular}

$\begin{array}{lrrr}\text { SAH } & 19 & 0 & 2 \\ \text { PPI } & 8 & 9 & 9 \\ \text { TJC } & 15 & 6 & 10 \\ \text { LW } & 9 & 6 & 3 \\ \text { TPF } & 11 & 14 & 12 \\ \text { SS } & 9 & 4 & 2 \\ \text { BDC } & 9 & 2 & 1 \\ \text { JK } & 14 & 10 & 7 \\ \text { W } & 10 & 3 & 4 \\ \text { AL } & 15 & 6 & 4 \\ \text { Subtotal } & 119 & 60 & 54 \\ \text { Total } & 248 & 195 & 208\end{array}$

Note-For explanations of abbreviations for events, see Table 1 . The last column shows the number of subjects completing the specific event recall questionnaire who described a specific event for each general event description. 
would be unlikely to try to base their estimates on different specific events within that category.

One factor that may contribute to specific event availability is event frequency. Table 3 indicates that the majority of estimates claimed to be based on the duration of a specific event were for the 10 high-frequency general event types. Similarly, the majority of the events described by the subjects in the specific event recall questionnaire were for the high-frequency general event types. Examination of the specific events recalled by the subjects in the specific event recall questionnaire indicated that a total of 48 different events were described for highfrequency general event types, compared to only 17 different events for the 10 low-frequency general event types.

The difference in the number of different events described for the high- and low-frequency event types is consistent with the suggestion made above that if subjects used a specific event availability strategy, they would use a greater variety of specific events when confronted with high-frequency general event descriptions. It was also suggested that this should produce an increase in betweensubject estimation variance for high-frequency events in comparison with low-frequency events: a result opposite that found in Experiment 2. Comparison of the standard deviations of the estimates for the 10 high- and lowfrequency general event types for both the specific event recall and duration estimation process questionnaires produced results consistent with those obtained in Experiment 2. Although analysis of covariance, with actual duration as the covariate, indicated that neither pair of adjusted means was significantly different, the highfrequency events' adjusted mean standard deviations (50.47 and 24.00 for specific event recall and duration estimation process questionnaires, respectively) were smaller than the low-frequency events' (105.07 and 181.32 , respectively) for both questionnaires.

These results imply that the subjects who stated that they had used the duration of a specific event as the basis for their duration estimate may not have actually done so. Subjects do not actually remember a specific event's actual duration very often, as is indicated by the results of Experiment 1. Hence, it appears that the subjects in this experiment who stated that they used a specific event's duration may have reconstructed event duration from general knowledge of the event category.

This reasoning accounts for another result obtained from the duration estimation process questionnaire. The medians of duration estimates reportedly based on specific events' durations correlated highly across the 20 events with the medians of duration estimates reportedly derived from the other four process categories $(\rho=.86$, $p<.01$ ). Moreover, rather similar moderate correlations were obtained when these two kinds of median estimates were separately correlated with actual event durationthat is, with the durations of the original specific events shown in Table 1 (specific event-based, $\rho=.59$, $p<.01$; four other processes, $\rho=.52, p<.05$ ).

\section{GENERAL DISCUSSION}

In line with Ornstein's (1969) "storage size" hypothesis, at least part of the variance in public event duration estimates appears to be accounted for by the subjects' event knowledge, with an increase in event knowledge producing an increase in the size of the estimated duration. However, because the actual durations of the events were generally underestimated and event knowledge decreased the size of the underestimation, event knowledge can be interpreted as increasing estimation accuracy. This interpretation of the part that event knowledge plays in duration estimation is markedly different from Ornstein's hypothesis of a direct relationship between event knowledge and estimated duration. Indeed, we found that knowledge of an event was not necessary for subjects to give a reasonably accurate estimate of its duration. Clearly, the estimation of public event duration is not based solely on the amount of stored event information.

The estimates obtained in this study do not appear simply to be guesses; on the contrary, they appear to be based on general event knowledge. Indeed, the predictions made on the basis of the proposed reconstructive model of duration estimation were largely confirmed in Experiment 2. Event duration reconstruction appears to involve the categorization of the target event, which allows access to general knowledge of that type of event.

General knowledge of a specific type of event appears to vary in relation to the number of specific events of that type encountered in the past. In Experiment 3, evidence was found that subjects can indeed recall and describe a reasonable number of events for some event categories, and it is likely that they sometimes made use of remembered specific events in their estimates of the durations of general events. The results, however, did not suggest that this was a frequent strategy.

Some knowledge of the duration of specific events may well be integrated with general knowledge of event categories. Specific events may form boundary markers. That is, the limits of a type of event's duration range may be defined by specific occurrences of the event type. These boundary events may be labeled as having an atypical duration; they may be either shorter or longer than the typical category event. Hence the duration of a specific event for which one has already experienced a number of category examples is perhaps only stored in memory if it is significantly different from that which is already stored for the event category.

Knowledge of boundary events probably allows a subject to adjust an inferred estimate if the estimate is made for that event, rather than for another category member. This reasoning may account for why duration was generally underestimated in Experiment 1 and why event knowledge was positively related to estimated duration. It is possible that some of the events used in Experiment 1 had atypically long durations (e.g., Events OUE, TJC, 
and RCF). Hence durations reconstructed from general event knowledge would be underestimates. Furthermore, if a subject knew of the atypical nature of an event, he or she might have corrected the estimate accordingly.

This reasoning may explain why durations in other studies (e.g., Douglas \& Blomfield, 1956; Mednick \& Shaffer, 1963) have generally consisted of overestimates. The events used in these studies may have had atypically short durations. This suggestion is based on the assumption that the duration of autobiographical events is reconstructed in a similar way to that shown for public events in this study. Results of another study conducted by the first author, however, suggest that this is a valid assumption (see Burt, 1990).

The formulation of a reconstructive model of duration estimation to explain the results of this study is not unexpected. First, most duration estimation research has required the estimation of rather meaningless intervals of time that do not permit a reconstructive strategy. It is thus perhaps unsurprising that Ornstein's model, which was developed to explain the results of experiments on the perception of brief time intervals, could not adequately explain the present results. Second, there is ample evidence that responses are often reconstructed rather than recalled. In relation to temporal information-specifically, to the recall of when an event has occurred-the dominant explanation consists of reconstruction, which incorporates the use of general time knowledge about natural temporal patterns, activity routines, and autobiographical and social information (see, e.g., Friedman \& Wilkins, 1985). The results of the present study suggest that event duration may be similarly reconstructed.

\section{REFERENCES}

ALLAN, L. G. (1977). The time order error in judgements of duration. Canadian Journal of Psychology, 31, 24-31.

Avant, L. L., \&yman, P. J. (1975). Stimulus familiarity modifies perceived duration in pre-recognition visual processing. Journal of Experimental Psychology: Human Perception \& Performance, 1. 205-213.

Baddeley, A. D., Lewis, V., Nimmo-Smith, I. (1978). When did you last...? In M. M. Gruneberg \& R. N. Sykes (Eds.), Practical aspects of memory (pp. 77-83). London: Academic Press.

BLOCK, R. A. (1978). Remembered duration: Effects of event and sequence complexity. Memory \& Cognition, 6, 320-326.

Bradburn, N. M., Rips, L. J., \& Shevell, S. K. (1987). Answering autobiographical questions: The impact of memory and inference on surveys. Science, 236, 157-161

Bratfisch, O., Ekman, G., Lundsberg, A., \& Kruger, K. (1971). Subjective temporal distance and emotional involvement. Scandinavian Journal of Psychology, 12, 147-160.

Brown, N. R., Rips, L. J., Shevell, S. K. (1985). The subjective dates of natural events in very-long-term memory. Cognitive Psychology, 17, 139-177.

Brown, N. R., Shevell, S. K., \& RIPs, L. J. (1986). Public memories and their personal context. In D. C. Rubin (Ed.), Autobiographical memory (pp. 137-158). Cambridge: Cambridge University Press.

BUFFARDI, L. (1971). Factors affecting the filled-duration illusion in the auditory, tactual, and visual modalities. Perception \& Psychophysics, 10, 292-294.
BURT, C. D. B. (1990). Reconstruction of the duration of autobiographical events. Manuscript submitted for publication.

BURT, C. D. B. (in press). Retrieval characteristics of autobiographical memories: Event and date information. Applied Cognitive Psychology.

Douglas, J. W. B., BLomfield, J. M. (1956). The reliability of longitudinal surveys. Millbank Memorial Fund Quarerly, 34, 227-252.

EISLER, H. (1976). Experiments on subjective duration 1868-1975: A collection of power function exponents. Psychological Bulletin, 83, 1154-1171.

Ferguson, R. P., \& Martin, P. (1983). Long-term temporal estimation in humans. Perception \& Psychophysics, 33, 585-592.

Fraisse, P. (1963). The psychology of time. New York: Harper \& Row.

Fraisse, P. (1984). Perception and estimation of time. Annual Review of Psychology, 35, 1-36.

FrankenhaeUSer, M. (1959). Estimation of time: An experimental study. Stockholm: Almquist \& Wiksell.

Friedman, W. J., WiLKins, A. J. (1985). Scale effects in memory for the time of events. Memory \& Cognition, 13, 168-175.

FURLONG, E. J. (1951). A study in memory. London: Thomas Nelson.

Hall, G. S., \& JASTROW, J. (1886). Studies of thythm. Mind, 11, 55-62.

Hellstrom, A. (1977). Time errors are perceptual. Psychological Research, 39, 345-388.

HoAGLAND, H. (1933). The physiological control of judgements of duration: Evidence for a chemical clock. Journal of General Psychol ogy, 9, 267-287.

Huttenlocher, J., Hedges, L., \& Prohaska, V. (1988). Hierarchical organization in ordered domains: Estimating the dates of events. Psychological Review, 95, 471-484.

KANE, L. S. \& Lown, B. A. (1986). Steven's power law and time perception: Effect of filled intervals, duration of the standard and number of presentations of the standard. Perceptual \& Motor Skills, 62 , 35-38.

Kemp, S. (1988). Dating recent and historical events. Applied Cognitive Psychology, 2, 181-188.

KoWAL, K. H. (1987). Apparent duration and numerosity as a function of melodic familiarity. Perception \& Psychophysics, 42, 122-131.

Lieury, A., Caplain, P., Jacquet, A., Jolivet, C. (1979). La contraction du temps dans la datation des souvenirs anciens. L'Anneé Psychologique, 79, 7-22.

Linton, M. (1975). Memory for real-world events. In D. A. Norman \& D. E. Rumelhart (Eds.), Explorations in cognition (pp. 376-404). San Francisco: W. H. Freeman

LofTus, E. F. (1979). Eyewitness testimony. Cambridge, MA: Harvard University Press.

Loftus, E. F., \& Marburger, W. (1983). Since the eruption of Mt. St. Helens, has anyone beaten you up? Improving the accuracy of retrospective reports with landmark events. Memory \& Cognition, 11, 114-120.

Loftus, E. F., Schooler, J. W., Boone, S. M., KLINe, D. (1987). Time went by so slowly: Overestimation of event duration by males and females. Applied Cognitive Psychology, 1, 3-13.

Mednick, S. A., \&haffer, J. B. P. (1963). Mothers' retrospective reports in child-rearing research. American Joumal of Orthopsychiatry 33, 457-461.

ORNSTEIN, R. E. (1969). On the experience of time. Harmondsworth, U.K.: Penguin

Pyles, M. K., Stolz, H. R., \& Macfarlane, J. W. (1935). The accuracy of mothers' reports on birth and developmental data. Child Development, 6, 165-176.

Rubin, D. C., Baddeley, A. D. (1989). Telescoping is not time compression: A model of the dating of autobiographical events. Memory \& Cognition, 17, 653-661.

Rule, S. J., \& CURTIS, D. W. (1985). Ordinal properties of perceived average duration: Simultaneous and sequential presentations. Journal of Experimental Psychology: Human Perception \& Performance, 11, 509-516.

SChiffman, H. R., \& Bobko, D. J. (1974). Effects of stimulus complexity on the perception of brief temporal intervals. Journal of $E x$ perimental Psychology, 103, 156-159. 
Schiffman, H. R., \& Bobko, D. J. (1977). The role of number and familiarity of stimuli in the perception of brief temporal intervals. American Journal of Psychology, 90, 85-93.

Thomas, E. A. C., Brown, I., JR. (1974). Time perception and the filled-duration illusion. Perception \& Psychophysics, 16, 449-458.

Thompson, C. P. (1982). Memory for unique personal events: The roommate study. Memory \& Cognition, 10, 324-332.

UNDERWOOD, G. (1975). Attention and the perception of duration during encoding and retrieval. Perception, 4, 291-296.
WAGENAAR, W. A. (1986). My memory: A study of autobiographical memory over six years. Cognitive Psychology, 18, 225-252.

WhITE, R. T. (1982). Memory for personal events. Human learning, $1,177-183$

WOODWORTH, R. S., \& SCHLOSBERG, H. (1954). Experimental psychology. New York: Holt.

(Manuscript received March 14, 1990;

revision accepted for publication September 26, 1990.) 